\title{
LÉXICO E CULTURA: ALGUNS APONTAMENTOS A PARTIR DA TRADUÇÃO DE “FOI ASSIM” DE NATALIA GINZBURG
}

\begin{abstract}
Edson Roberto Bogas Garcia (UNESP/IBILCE/UNIFEV) edsonbog@terra.com.br Claudia Zavaglia (UNESP/IBILCE) zavaglia@unesp.ibilce.br
\end{abstract}

\begin{abstract}
RESUMO: Atualmente, os estudos lexicológicos têm demonstrado que as unidades lexicais possuem a fundamental característica de representar a realidade linguística cultural e social de uma determinada comunidade. A partir desse pressuposto, este trabalho tem como objetivo ponderar acerca da importância da seleção lexical na tradução do romance "È stato cosi”, da escritora italiana Natalia Ginzburg, traduzido para o português com o título "Foi assim". A obra em questão, no caso, é marcada pela maneira de representar a sociedade por meio de um realismo cujas raízes se firmam na angústia existencial do nosso tempo. Serve, portanto, para os pontos a que se propõe esta pesquisa. Com isso, pretende-se, por meio dessa análise, constatar que o resultado de uma tradução eficiente, além de considerar a empatia tradutor-obra, deve, indubitavelmente, levar em consideração os conhecimentos léxico-culturais desse profissional. O processo, assim desenvolvido, é um estudo que proporciona criteriosas descobertas acerca de áreas de pesquisas promissoras as quais podem possibilitar a difusão de obras para que comunidades tenham acesso, cada vez mais, a boas leituras.
\end{abstract}

Palavras-chave: Léxico. Cultura. Romance italiano. Tradução.

ABSTRACT: Lexicological studies have currently shown that lexical units have the fundamental aspect of representing the linguistic, cultural and social reality of a given community. Based on these assumptions, the present work is aimed at reflecting on the relevance of the lexical choices in the translation of "È stato cosi", a novel by Italian writer Natalia Ginzburg, translated into Portuguese as "Foi assim". One of the strong features of the novel is the way it represents society through a realism with roots in the existential anxiety of our time. It is, therefore, purposeful to the points this work aims to discuss. Thus, with the analysis proposed, our purpose is to attest that an effective translation, in addition to being the result of the translator-text relationship, undoubtedly reflects the translator's lexical-cultural knowledge. Also, the result of the analysis might reveal insightful findings related to promising research areas that can contribute to the diffusion of literary works, so that communities have more and more access to good reading. 
Key-words: Lexicon. Culture. Italian novel. Translation.

\author{
(...) \\ Cantando amor, os poetas na noite \\ Repensam a tarefa de pensar o mundo. \\ E podeis crer que há muito mais vigor \\ No lirismo aparente \\ No amante Fazedor da palavra \\ Do que na mão que esmaga. \\ A IDÉIA é ambiciosa e santa. \\ E o amor dos poetas pelos homens \\ é mais vasto \\ Do que a voracidade que nos move. \\ E mais forte há de ser \\ Quanto mais parco \\ Aos vossos olhos possa parecer.
}

Hilda Hilst

\title{
Introdução: léxico e cultura
}

$\mathcal{A}$ partir da década de 50, Matoré (1953), seguindo ainda a linha estruturalista, passa a considerar os aspectos sociais no estudo do léxico. Esse linguista via a Lexicologia como uma disciplina sociológica e considerava a palavra não como um objeto isolado, mas como parte de uma estrutura social. Segundo ele, o léxico é um fato social. É o espelho de uma sociedade e para lá dos muros dela a linguagem não encontra expressão.

Os estudos da Lexicologia, com base nesse preceito, têm demonstrado que o léxico possui a fundamental característica de representar a realidade linguística cultural e social de uma determinada comunidade. É por meio dele que todo saber adquirido em vários momentos da vida dos indivíduos é transmitido às gerações seguintes. Assim sendo, os vocábulos têm a função de fazer perdurar sentimentos, emoções e conhecimentos. 
Acrescentamos que, por pertencer ao universo social, diferentemente da gramática da língua, o léxico torna-se um sistema aberto e em expansão, impossível de cristalizar-se, a não ser que a língua morra.

De acordo com Vilela (1994, p. 6),

O léxico é a parte da língua que primeiramente configura a realidade extralinguística e arquiva o saber linguístico duma comunidade. Avanços e recuos civilizacionais, descobertas e inventos, encontros entre povos e culturas, mitos e crenças, afinal quase tudo, antes de passar para a língua e para a cultura dos povos, tem um nome e esse nome faz parte do léxico. O léxico é o repositório do saber linguístico e é ainda a janela através da qual um povo vê o mundo.

A definição acima corrobora com Carvalho (2001), que diz que língua e cultura formam um todo indissociável e que "no caso da língua e da cultura maternas, esse todo não é ensinado em nenhum lugar especial, mas adquirido ao sabor dos acontecimentos cotidianos" (CARVALHO, 2001, p. 100). A autora pondera que o componente semântico-lexical revela com maior clareza as divergências entre os usos por diferentes comunidades linguísticas.

O jogo é sempre o mesmo: no momento da comunicação, entender um signo é construir uma linha de demarcação entre os que compartilham o sentido evocado e os que ficam excluídos. O implícito (cultural) desempenha um papel decisivo, impondo uma fronteira eficaz e discreta entre os que compreendem e os que não compreendem o sentido total da mensagem. A fronteira cultural não é apenas a das nações, nem sequer a da língua: pode ser regional e até mesmo grupal. (CARVALHO, 2001, p. 102).

Partimos, no presente trabalho, para elucidar o que se entende por cultura, das seis teorias descritas por Duranti (2000, p. 47) em que a linguagem desempenha um papel decisivo:

a) a cultura é aprendida e transmitida de geração em geração mediante a comunicação linguística. Dessa forma, ninguém nasce com uma cultura, mas, ao contrário, adquire-a por meio das pessoas com quem convive; 
b) a cultura como conhecimento de mundo, compartilhado entre os membros de uma comunidade;

c) a cultura como comunicação. Aquela conecta indivíduos, grupos, situações e objetos com outros grupos, situações e objetos. Nessa perspectiva, a comunicação não apenas representa, mas também indica alguma coisa, pressupõe, deduz;

d) a cultura como um sistema de mediação. O homem utiliza-se de ferramentas para produzir um trabalho ou interagir com o mundo social ou físico. Coexistem a cultura dos objetos materiais como as ferramentas de trabalho, bem como aquela de sistemas de crenças e códigos lingüísticos como mediadores entre o homem e seu entorno;

e) a cultura como um sistema de práticas. Ela existe por meio de uma prática rotineira que inclui as condições materiais e, também, pela experiência dos homens no seu meio familiar;

f) a cultura como um sistema de participação. Usar uma língua significa participar em interações com o mundo que nos cerca. A cultura é, nessa medida, um sistema de participação em que os indivíduos de uma comunidade compartilham os recursos existentes como as crenças, a linguagem, os costumes, etc.

Sabemos, no entanto, que a relação possível entre léxico e cultura não se esgota aí. Dessa maneira, apresentar uma definição totalizadora é bastante complexo. No entanto, com o levantamento das proposições acima, podemos perceber, com maior acuidade, que o léxico desempenha um papel decisivo em uma sociedade.

\section{Tradução}

À primeira vista, a tradução literária (e aqui generalizamos para outros tipos de tradução) poderia ser considerada uma tarefa fácil: com o domínio 
que se tem sobre dois idiomas e, com a ajuda de dicionários, verte-se o texto de partida (no caso em questão a língua italiana) para o texto de chegada (língua portuguesa). Essa é uma ideia generalizada da literalidade sonhada por produtores de programas para computadores que, até hoje, não surtiu grandes efeitos práticos. Paes (1990, p. 116) esclarece a questão quando diz que: "Pelo simples fato de ter sido feita e publicada, tradução alguma pode aspirar à dignidade de tal estado. Para tanto, deve fazer-lhe jus. Não o fazem, obviamente, as traduções que, por incompetência, fiquem aquém do horizonte do possível".

Não obstante, o trabalho de pesquisa requer mais do que isso. Devido à riqueza vocabular e cultural-literária de cada país, torna-se importante um conhecimento, por parte do tradutor:

a) dos aspectos literários e históricos de cada nação;

b) além do conhecimento linguístico, de um "saber" cultural que permite perspassar os limites da literalidade e

c) das tendências peculiares, na linguagem, dos estilos e modismos da época a ser enfocada.

A respeito disso, Aubert (1994) salienta que:

[...] mas todos esses elementos - lexicais, morfológicos, sintáticos e textuais - por si só não proporcionam uma imagem completa do conceito de visão de mundo, tal como se manifesta ou se institui na língua. Vivenciar o mundo é algo que se faz, através da linguagem, instituindo relações de intimidade com esse mundo.

Antes de prosseguir, abrem-se aqui parênteses para acrescentar, por meio das palavras de Paes (1990, p. 116), um item (d) à lista acima:

Além de cultura literária e conhecimento de línguas, o aferidor deve ter certa intimidade com os procedimentos tradutórios, seja pela sua prática, seja pela leitura regular de traduções de nível, por via das quais tenha podido adquirir uma noção da natureza e dos limites do traduzir (PAES, 1990, p. 116). 
A partir desses dados, o presente artigo analisa, para comprovar tais observações, as escolhas lexicais de alguns trechos de É stato così, traduzida no Brasil com o título Foi assim, um dos primeiros romances da escritora Natalia Ginzburg.

\section{Natalia Ginzburg no contexto literário-cultural italiano e a escolha lexical na tradução de "È stato cosi”"}

Grandes autores da literatura italiana contemporânea que compreende, mais especificamente, a produção do início do século XX até os nossos dias, sempre tiveram grande acolhida por parte dos leitores brasileiros. A leitura de obras de escritores desse período, como Alberto Moravia, Elio Vittorini, Leonardo Sciascia, Italo Calvino, entre outros, contribuiu para que muitas pessoas pudessem conhecer o desenvolvimento da cultura italiana, com seus problemas e soluções. Períodos densos como, por exemplo, os que envolvem as duas guerras mundiais, o fascismo, a luta dos italianos para a liberação de seu país e que marcaram uma profunda transformação da nação, preparando-a para os novos avanços sociais, culturais e políticos.

Apesar de não figurar entre os grandes nomes estudados pelos

críticos, Natalia Ginzburg vem merecendo, cada vez mais, destaque por parte de estudiosos italianos, principalmente a partir dos anos Cinqüenta, quando a sua presença começa a afirmar-se na literatura italiana.

Aqui, no Brasil, particularmente, com relação aos livros destinados ao estudo da língua italiana usados pelos nossos estudantes, muito são os que incluem textos da autora.

Sua formação literária se desenvolve num ambiente e num período histórico densos: a conturbada época em que se configura o pós-guerra. 
Desse período, traz consigo a sensação das profundas mudanças no povo italiano e na sua pátria:

[...] quando lembramos daqueles anos, lembramos do bem-estar junto com os desconfortos, o frio, a fome e o medo, que naqueles dias não nos deixavam nunca. $O$ fascismo tinha duas faces, a imbecilidade e a perversão. Todos víramos a imbecilidade, há um bom tempo, mas a perversão a entendemos agora, e em todos nasceu o sentimento de que estávamos saturados de imbecilidade e presos na perversão. $O$ pensamento que reinava constantemente na mente de cada um era liberar o mundo daquelas trevas carcerárias [...] . As palavras "pátria" e "Itália" que nos nausearam tanto entre as paredes da escola, porque vinham sempre acompanhadas pelo adjetivo "fascista", cheias de vazio, nos apareceram, de repente, sem adjetivos e tão transformadas que nos pareceu tê-las escutado pela primeira vez. De repente, nos nossos ouvidos soaram como verdadeiras. Estávamos ali para defender a pátria e a pátria eram aquelas ruas e aquelas praças, os nossos entes queridos e a nossa infância, e todas as pessoas que passavam (GINZBURG, 1964, p. 8).

Por participar da atmosfera que envolve quase todas essas correntes, nunca se propôs a aderir a nenhuma delas, produzindo suas obras numa linha de constante fidelidade a si mesma. "Natalia Ginzburg é criatura de seu tempo em cada momento e segundo uma perspectiva que ultrapassa os limites sempre restritos dos vários "ismos" literários." (CLEMENTELLI, 1986, p. 107). Uma escritora consciente de seu relacionamento inato com a arte de escrever, mas, ao mesmo tempo, constantemente levada por um estado de forte tensão moral que a conduziu a um progressivo aprofundamento das razões da profissão.

Um itinerário que se mantém fiel, no nível temático, na representação da inevitável solidão humana, tratada através de um tom narrativo simples, real e muitas vezes irônico, que toma forma na problemática dos relacionamentos familiares.

Segundo Marabini (1995, p. 24), "alguns livros dedicados aos membros da casa, à casa em si, aos hábitos cotidianos do grupo familiar, estão 
seguramente entre os melhores da segunda metade do século XX e são livros, além disso, de um não-preconceito que é a prova última da verdade”.

Apesar da aparente monotonia temática, muito diversos serão os resultados estilísticos de cada obra: tramas sem diálogos, diálogos absolutos, formas epistolares, experiências teatrais e pesquisa de campo. Peças de um quebra-cabeças que permitem dividir em dois momentos a criação literária da escritora, que apresenta um divisor de águas preciso: Lessico famigliare. No primeiro, a busca da autobiografia (não casual) e no segundo, o distanciamento desse estilo (casual).

Nesse primeiro momento - que vai de Un'assenza a Lessico famigliare, em que a autora busca o aprimoramento do estilo autobiográfico , se encontra È stato così, publicado num período de grandes transformações mundiais e que tem como reflexo, na literatura, na maneira de representar a sociedade através de um realismo cujas raízes se firmam na angústia existencial do nosso tempo.

Dentro dessa concepção de arte, o interesse em apresentar e traduzir o romance '̇ stato così, nasceu pela surpreendente capacidade da escritora de desenvolver a estória de uma mulher que analisa, passo a passo, momento a momento, os anseios e frustrações de uma vida solitária e infeliz. Uma maneira seca e minuciosa de entender as reações humanas que termina sendo resolvida inteiramente na verbalização das motivações psicológicas.

A pesquisa lexical para a realização do ato tradutório, por conseguinte, teve de atentar a essa elaboração para que não se perdesse essa busca constante na caracterização do narrador e da densidade das personagens do romance. 


\section{Amostra do corpus}

Abaixo, selecionamos uma parte (que representa um percentual bastante significativo de ocorrência) do corpus trabalhado.

1. Colocação dos adjetivos (adotou-se a estrutura $S+A$ na língua portuguesa ao invés de $\mathrm{A}+\mathrm{S}$, comum, na língua italiana)

"Poi mi son messa a letto e avevo un sonno tremendo e m'addormentavo um minuto ma mi svegliavo con quell'orrendo dolore.”

"Depois me deitava e tinha um sono tremendo e adormecia um minuto, mas acordava com aquela dor horrível."

"Era una tetra pensione con delle tappezzerie oscure, (...)."

"Era uma pensão tétrica com tapeçarias escuras, (...)."

\section{Termos mais apropriados}

2.1. ciocolatini $=$ bombons em vez de chocolatezinhos.

"Eppure mi portava dei libri e dei cioccolatini e pareva molto molto contento di stare con me."

"Contudo me trazia libros e bombons e parecia muito muito contente de estar comigo."

2.2. armadio $=$ guarda-roupa em vez de armário.

“(...)perché credeva che la vecchia sarebbe sbucata fuori a un tratto dall'armadio e l'avrebbe accecata".

“(...)porque acreditava que a velha, de repente, sairia do guarda-roupa e a cegaria."

2.3. salutava $=$ acenava em vez de saudava.

“(...)e lui che si sporgeva dal finestrino e salutava col fazzoletto."

“(...)e ele que se debruçava na janela e acenava com o lenço." 
2.4. trovarti $=$ visitá-la em vez de encontrá-la.

“-(...).Tornerò qualche volta a trovarti, se non ti dispiace."

“-(...).Voltarei algumas vezes para visitá-la, se não lhe desagrada."

2.5. riaprivano le scuole $=$ recomeçavam as aulas em vez de reabriam as escolas.

“(...)perché pensavo che dovesse immaginarlo che io ero tornata, dato che riaprivano le scuole.”

“(...)porque pensava que devia imaginar que eu chegara, pois recomeçavam as aulas."

\section{Diferença de frequência de uso das palavras nas duas línguas}

\section{1. matrimonio $=$ casamento em vez de matrimônio}

"E allora in quel momento ho pensato che il nostro matrimonio era un disastro."

"E então, naquele momento, pensei que o nosso casamento era um desastre."

3.2. funerale $=$ enterro em vez de funeral

"Al funerale non ci sono andata perché la vecchia aveva lasciato scritto che al funerale non voleva nessuno,(...)."

"Não fui ao enterro porque a velha deixara escrito que não queria ninguém no enterro, (...)."

\section{Falsos amigos}

4.1. fede $=$ aliança (de casamento) e não fé. A confusão pode surgir do fato que em algumas regiões da Itália é mais usual o termo para aliança.

"Mi son tolta la fede e l'ho messa in tasca."

"Tirei minha aliança e a coloquei no bolso." 
5. Emprego do imperfeito do inidicativo (em italiano) $\mathrm{x}$ emprego do pretérito perfeito do indicativo (em português)

"Ma dopo che ci siamo sposati non disegnava più la mia faccia. Disegnava degli animali e dei treni."

"Mas depois que nos casamos não desenhou mais o meu rosto. Desenhava animais e trens."

6. Emprego do futuro do pretérito composto do indicativo (em italiano) $\mathrm{x}$ emprego do futuro do pretérito simples do indicativo ( em português)

"Avremmo avuto tanti bambini e Alberto sarebbe venuto a trovarci e avrebbe portato un grosso panettone a Natale e sarebbe stato contento(...)." "Teríamos muitos filhos e Alberto viria nos visitar e traria um grande panetone no Natal e ficaria contente(...)."

7. Emprego do imperfeito do indicativo (em italiano) $\mathrm{x}$ emprego do pretérito imperfeito do subjuntivo (em português)

"Sul principio non parlavamo della bambina, ma poi abbiamo cominciato a parlarne e lui m'ha detto che forse mi faceva bene parlarne molto a lungo com lui."

"No começo não falávamos sobre a menina, mas depois começamos a falar e ele me disse que talvez me fizesse bem falar sobre ela com ele." 


\section{Hábitos diferentes nos dois países}

"M’ha sbucciato un'arancia, ma non avevo voglia de mangiarla(...)." "Descascou-me uma laranja, ma não tinha vontade de comê-la(...)."

Observação: Em vez de comer, em português, seria mais comum chupar. Só que na Itália a laranja se come em gomos e não se chupa, como no Brasil.

9. Lugares específicos de Turim (embora no romance não seja especificado que a ação se desenrole nesta cidade)

"Andavamo a camminare lontano lungo il fiume o nelle vie di barriera,(...)." "Íamos caminhar longe ao longo do rio ou nas ruas da barreira alfandegária, (...)"

Observação: Turim é uma das poucas cidades da Itália que ainda guarda vestígios urbanos do local em que era cobrado esse imposto sobre os produtos, que corresponde ao atual ICM, imposto sobre circulação de mercadoria.

“(...)aspettava tutto l'anno la sera della Consolata per appendere al balcone quei lampioncini(...).”

“(...)esperava o ano inteiro a noite de Nossa Senhora da Conceição para pendurar aqueles lampeõzinhos(...)"

Observação: Nossa Senhora da Conceição é padroeira da cidade de Turim.

\section{Conclusão}

A importância do tema pesquisado dá-se por existir uma parte considerável de pesquisadores em línguas estrangeiras os quais têm se dedicado a esse tipo de estudo. É necessário, por isso, estar consciente de que a escolha de uma obra literária para desenvolver uma pesquisa e, 
posteriormente, sua tradução, em cursos de pós-graduação, requer do investigador uma série de procedimentos para que seu trabalho possa ter o resultado que se espera na língua de chegada (basta pensarmos na importância do léxico, dos postulados teóricos da tradução, das tramas do texto literário, etc).

Não se trata de um trabalho que, a priori, tenha um objetivo comercial. Por isso, a seleção do texto deve, de antemão, propiciar a satisfação que os teóricos de Metodologia de Pesquisa insistem em defender para se defender qualquer tipo de trabalho científico. Dessa maneira, quanto mais prazerosa a leitura e quanto maior a identificação entre narrativa-tradutor, melhor será o desempenho em tentar descortinar o universo linguístico e extralinguístico presentes no texto.

Apesar de ser uma pesquisa que requer um estudo pormenorizado das teorias acima descritas, a ponte percorrida entre LP e LC pode possibilitar que um número de leitores interessados na Literatura Italiana e que não conhecem o idioma de tal forma a entendê-lo em textos mais complexos, possa ter acesso a uma obra densa de significados para a cultura da Itália.

O processo, assim desenvolvido, longe de possuir baixo teor científico, é um estudo que proporciona criteriosas descobertas acerca de áreas de pesquisas promissoras as quais podem possibilitar a difusão de obras para que comunidades tenham acesso, cada vez mais, a boas leituras.

\section{Referências bibliográficas}

AUBERT, Francis. As (in)fidelidades da traducão: servidões e autonomia do tradutor. 2. Ed. Campinas (SP): Editora da Unicamp.

BUARQUE DE HOLANDA, A.F. Novo dicionário da língua portuguesa. Rio de Janeiro: Nova Fronteira, 2001.

CARVAlHO, Nelly de. Publicidade: A linguagem da sedução. 3 ed. São Paulo: Ática, 2001 
CLEMENTELLI, E. Invito alla lettura di Natalia Gin₹burg. Milano: Mursia, 1972-1986.

CROCENZI, L. Narratrici d'oggi. Cremona: Mangiarotti, 1966

DE NICOLA, F., ZANNONI, P.A. Scrittrici d'Italia. Genova: Costa \& Nolan, 1995.

DURANTI, Alessandro. Antropologia linguística. Tradução de Pedro Tena. Madrid: Cambridge University Press, 2000.

FERNANDES, F. Dicionário de regimes de substantivos e adjetivos. Porto Alegre: Globo, 1980.

Globo, 1983.

Dicionário de verbos e regimes. Porto Alegre/Rio de Janeiro:

GARBOLI, C. "Introduzione". In: Cinque romanzi brevi e altri racconti. Torino: Einaudi, 1964. p. IV-XII.

GINZBURG, N. Cinque romanæi brevi e altri racconti. Torino: Einaudi, 1964.

MARABINI, Claudio Marabini. Gli ultimi cinquant'anni di narrativa femminile in Italia. In: NICOLA, Francesco de; ZANONI, Pier Antonio Zanoni. Scrittrici d'Italia. Atti del Convegno nazionale di Studi (Rapallo, 14 maggio 1994). Genova: Costa \& Nolan, 1995.

MATORÉ,George. La Méthode en Léxicologie. Paris: Didier, 1953.

PAES, José Paulo. Tradução a ponte necessária: aspectos e problemas da arte de traduzir.

RÓNAI, P. A tradução vivida. Rio de Janeiro: Educom, 1976.

VILELA, Mario. Estruturas léxicas do português. Coimbra: Livraria Almedina, 1979.

Léxico e gramática. Coimbra: Almedina, 1995.

ZINGARELLI, N. Il Nuovo Zingarelli, Vocabolario della lingua italiana. 11 ed., Bologna: Zanichelli, 1984. 